\title{
A evolução epistemológica do conceito de avaliação documental na arquivística e sua importância para a construção da memória
}

\author{
Mariana Lousada \\ marianalousada@hotmail.com \\ Universidade Estadual Paulista (UNESP)
}

\begin{abstract}
Resumo: Este trabalho revisita o conceito e o processo de avaliação documental e sua influência na construção da memória. Apresenta uma análise nas relações entre a memória e os sistemas de arquivos, bem como a materialidade dessa memória, o documento. Realiza uma revisão epistemológica na literatura Arquivística a fim de comparar correntes de pensamentos clássicas e pós-modernas, acerca da avaliação documental e do conceito de Macroavaliação proposto por Terry Cook, também reflete sobre a neutralidade dos arquivistas no referido processo. Conclui que a avaliação documental pode ser considerada como um dos elementos responsáveis pela construção da memória institucional ou social, uma vez que garante o encaminhamento dos documentos de valor secundário ao arquivo permanente contribuindo com a formação do patrimônio arquivístico, e ainda que o arquivista emprega, consciente ou inconscientemente, seus atributos pessoais e profissionais na execução das suas tarefas, portanto, não pode ser considerado um profissional neutro ou imparcial.
\end{abstract}

Palavras-chave: Memória; Avaliação de documento; Macroavaliação; Arquivista.

Abstract: This paper revisits the concept and process of appraisal document and its influence on the construction of memory. Presents an analysis of the relationship between memory and file systems, as well as the materiality of this memory, the document. Performs an epistemological literature review Archivist Science to compare current thoughts classical and post-modern, documentary about the assessment and the concept of Macroappraisal proposed by Terry Cook, also reflects on the neutrality of archivists in that case. We conclude that the assessment document can be consider as one of the elements responsible for the construction of social or institutional memory, since it ensures the routing of documents of secondary value to the permanent file contributing to the formation of the archival heritage, and even employs the archivist, consciously or unconsciously, their personal attributes and professional in carrying out their tasks, therefore, can't be considered a professional neutral or impartial.

Keywords: Memory; Appraisal document; Macroappraisal; Archivist. 


\section{INTRODUÇÃO}

A proposta desse trabalho é colocar em discussão por meio de uma análise epistemológica a evolução do conceito da avaliação documental e sua interferência/influência na construção da memória. Para tanto, busca-se o início da noção de avaliação, bem como suas diversas abordagens teóricas.

Podemos considerar, em linhas gerais, que a eleição da memória consiste, de fato, em decidir, diante de um conjunto de dados, eventos ou informações, quais devem ser privilegiados e quais podem ser abandonados ao possível cancelamento. Segundo Colombo (1991, p. 89) a escolha nas sociedades fundadas na oralidade, era necessariamente fundamentada em critérios de valor social: a mitologia e o saber histórico não são, no fim das contas, nada além das construções memoriais instituídas com base em axiologias opostas; a memória oral baseada na tradição sempre parte do pressuposto de que aquilo que foi memorizado no início deva ser continuamente transmitido.

Assim, podemos estabelecer um campo para o entendimento e reconhecimento dos motivos pelos quais alguns documentos são conservados e, principalmente, os valores atribuídos e as diretrizes institucionais que elegem quais documentos são considerados socialmente relevantes a ponto de se justificar a sua preservação permanente.

A noção/conceito de memória dentro dos arquivos tende a ser referida como o processo de avaliação e seleção dos documentos arquivísticos (JARDIM, 1995). Deste modo, buscou-se visualizá-lo a partir das dimensões teórica, metodológica e política.

\section{A NOÇÃO/CONCEITO DE MEMÓRIA NOS SISTEMAS DE ARQUIVOS}

Desde os primórdios o homem busca meios de registrar e conservar suas memórias, sob as mais diferentes formas. Primeiramente, o modo de preservação era sob a forma oral, depois através dos símbolos gráficos. De acordo com Lodolini (1989) citado por Rousseau e Couture $(1998$, p.34) a memória assim registrada e conservada constituiu e constitui ainda a base de toda e qualquer atividade humana: a existência de um grupo social seria impossível sem o registro da memória, ou seja, sem arquivos, a própria vida não existiria, pelo menos sob a forma que conhecemos.

Essa afirmação de Lodolini traduz perfeitamente o conceito de memória aplicado aos arquivos. Trata-se em primeiro lugar, da memória necessária a qualquer administração saudável, mas também daquela que irá ser útil às gerações vindouras. Era antes de tudo fruto 
das atividades mais recentes que os governos, desde os tempos antigos, faziam apelo, registrando os tratados, as contas e os privilégios. Os arquivistas do século XIX destacaram posteriormente sua importância utilizando essas mesmas informações, mas para fins de reconstituição (ROUSSEAU; COUTURE, 1998, p.34).

A noção/conceito de memória gera inúmeras discussões, pois se trata de uma palavra utilizada por biólogos, médicos, filósofos, sociólogos, antropólogos, historiadores, psicólogos e cientistas da informação, frequentemente empregada em contextos diversos. O sentido original do termo é a capacidade humana de guardar no cérebro impressões das experiências vividas (LOPES, 2009, p. 120-121).

Para Colombo (1991, p. 83) "a memória se define especificamente em função da ordem de colocação temporal dos objetos que recordamos". Ou seja, está diretamente relacionada aos objetivos recordados. Tanto a memória como a história não estão isoladas, e sim, inseridas em um tempo e espaço determinado, que estabelece redes de relações formando o contexto social do objeto lembrado. Não podemos entender esses objetos simplesmente como "coisas", e sim como fenômenos recordados.

No momento que recordamos algum fato ou objeto, imediatamente alocamos essa lembrança no tempo e no espaço e as relações que construímos entre todas essas lembranças nos darão o contexto da nossa memória, que permitirá visualizarmos uma situação completa ou parcial. Mas é importante salientar que essa alocação que fazemos, é também pautada na memória coletiva, mas como é uma atividade arbitrária, construída e estabelecida por nós mesmos, não significa que seja real, mas se acreditamos muito nessa conexão que estabelecemos para nós ela passa a ser verdadeira, mas não real.

No contexto dos sistemas de arquivos, os registros documentais - suportes convertem-se na materialidade desta memória, dimensionada pelo recorte temporal e marcada pelo processo historiográfico.

No entanto, esses espaços institucionalizados não possuem como característica, elementos próprios à memória espontânea, por encontraram-se vinculados primeiramente aos interesses de seus órgãos fundadores.

Para Pierre Nora (1981 apud MENESES, 1992, p. 31):

\footnotetext{
A memória nas sociedades anteriores à contemporânea era uma memória espontânea, viva, realizada, experiência internalizada. Entretanto ela vai progressivamente se transformando em uma memória que se dá fora das pessoas, fora da experiência. De ambientes de memória passa-se a lugares de memória. Que lugares de memória são esses? São espaços, coisas, pessoas, instituições, cerimônias, símbolos, etc., que condensam memória. Ela não está mais difusa nas pessoas, mas sintetizada em plataformas precisas e limitadas, os lugares de memória.
} 
Fausto Colombo (1991) em sua obra Os arquivos imperfeitos, demonstra que a atual sociedade caracterizada pela "informação e pela tecnologia" busca incessantemente pela memória, como uma forma de resgatar o passado marcado pela destruição. "Como convém a um século que conheceu duas grandes catástrofes bélicas e vive no terror de um próximo e irreversível declínio, nossa era parece estar dominada pela obsessão da memória" (COLOMBO, 1991, p. 17).

O autor também busca redefinir os significados dos arquivos nesta nova sociedade, focando, sobretudo, os documentos eletrônicos. Nesse sentido, aponta a fragilidade que a noção/conceito de memória adquire na contemporaneidade, bem como nas mudanças ocorridas nas compreensões de "arquivos labirintos" (cheios de estantes e galerias a serem decifradas, organizados por bancos de dados e acessíveis a poucos) e dos documentos como "tesouros". Hoje ainda prevalece, segundo o autor, o caráter elitista do arquivo, o acesso limitado às fontes, ambiguamente articulado à existência de uma busca pela memória associada a um direito assegurado a todos os sujeitos históricos, à constituição de identidades plurais (MARTINS, 2004).

Outra observação importante que a obra suscita é a de que os arquivos só alcançam suas finalidades relacionadas à memória quando interpretados pelos pesquisadores. Em outras palavras, a organização documental e a produção do conhecimento histórico são operações intrínsecas e precisam proceder integradamente. A seleção documental não deve reproduzir a tendência atual, caracterizada pelo excesso de informação, com os seus efeitos perversos de estagnação, muito mais do que de ação reflexiva.

Segundo Lopes (2009) é preciso estabelecer uma nítida separação entre o conceito de memória e o conceito de informação registrada para a salvaguarda/preservação dos arquivos, tal qual sejam suas idades, naturezas, proveniências ou suportes. Os documentos de arquivo não são o equivalente a uma ou mais memórias, nem mesmo parte da memória ou das memórias. Há diferenças substanciais entre o estabelecimento de um sistema de arquivos para uma organização e o fato de contar a sua história. Essas duas atividades são realizáveis, mas implicam tarefas distintas.

O autor acredita que para o arquivista é mais indicado ter em conta o sentido filosófico, biológico e psicológico do termo memória, isto é, a capacidade humana, e de outras espécies, de reter, no seu córtex, suas representações do mundo. As outras utilizações do termo têm características metafóricas, como sustenta Le Goff, e por vezes irracionais de acordo com que se pensa sobre o assunto (LOPES, 2009, p. 121).

A preservação do acervo documental, suas formas de organização e disseminação, além de permitir o exercício imediato da cidadania, possibilita a construção e o resgate da 
memória coletiva, social, nos diversos níveis e leituras possíveis: ela será sempre uma construção e, na maior parte do tempo, são os registros dos discursos oficiais.

\section{PERSPECTIVA hISTÓRICA E CONCEITUAL DA AVALIAÇÃO DOCUMENTAL NA TEORIA ARQUIVÍSTICA}

Diante das diversas colocações sobre as questões relacionadas à memória, faz-se necessário dimensionar como o processo de avaliação documental pode se tornar responsável pela construção da memória social, histórica e individual, e consequentemente, de que forma se constitui a formação do patrimônio arquivístico e como este teria a capacidade de 'expressar e refletir a memória' ou de permitir 'escrever a história'.

A avaliação documental é considerada dentro da área como um fenômeno recente, haja vista que durante séculos as instituições conservavam documentos que refletiam tanto testemunhos de seus direitos como de seus privilégios. Não havia um processo avaliativo que estudasse a real necessidade de preservação dos mesmos levando em consideração outros critérios de salvaguarda e de preservação. Todavia, a partir da segunda guerra mundial com o desenvolvimento tecnológico e a explosão documental essa questão começa a ganhar notoriedade.

A avaliação de documentos pode ser compreendida de distintas maneiras, primeiro como um conceito, uma vez que a teorização e reflexão são necessárias para a consolidação da área, também como uma prática, pois muitas instituições e, consequentemente profissionais não a realizam com base em nenhuma normativa ou instrumento que a justifique, e por fim, como um processo, pois poderia ser iniciada no momento da produção documental prevenindo a acumulação excessiva.

De acordo com a publicação do Conselho Nacional de Arquivos (2001, p.42) constituise em atividade essencial do ciclo de vida documental arquivístico, na medida em que define quais documentos serão preservados para fins administrativos ou de pesquisa e em que momento poderão ser eliminados ou destinados aos arquivos intermediário e permanente, segundo o valor e o potencial de uso que apresentam para a administração que os gerou e para a sociedade.

Pode-se discutir a avaliação documental a partir da reflexão de alguns autores, como por exemplo, Jenkinson (1922) que iniciou seus estudos na área a partir de trabalhos com arquivos medievais, o que acabou por influenciar sua posição mais rigorosa. Segundo ele, o arquivista não deveria participar da avaliação, uma vez que, seus pressupostos poderiam interferir na qualidade da conservação e na integridade dos arquivos e dos documentos, por 
isto, este trabalho deveria ser de responsabilidade dos administradores. É importante ressaltar que a posição adotada pelo autor deve ser contextualizada no espaço e no tempo, portanto, reflexos desse recorte temporal.

Schellenberg (1956) foi o primeiro pesquisador a analisar mais cuidadosamente a avaliação, o que proporcionou um progresso significativo para a Arquivística, preocupada, até o momento, com questões relacionadas à custódia, descrição e classificação dos documentos.

É a partir de suas obras que se iniciam os questionamentos sobre a responsabilidade do arquivista frente à racionalização e a produção dos documentos, já que seu papel até então era focado na questão histórica. A partir desta nova perspectiva da profissão, a avaliação passa a ser de responsabilidade do arquivista. De acordo com o autor, a análise deve ser a essência da avaliação, considerando a função pela qual foi criado o documento, buscando identificar valores e atributos, segundo o seu potencial de uso. No entanto, ressalta que não se reduz a um processo mecânico e nem deve ser aceita pela impossibilidade real de se conservar tudo. Também pondera que não se trata de um processo subjetivo, baseado na intuição ou em critérios de valor do avaliador, e sim, em critérios de valores consistentes, porém, não absolutos ou finais.

Schellenberg inovou ao criar uma nova forma de categorizar em dois níveis o valor atribuído aos documentos: valor em primário (administrativo-probatório) e secundário (histórico-cultural-informacional). Segundo ele era essencial uma nova definição do arquivo enquanto instituição, capaz de responder as demandas dos arquivistas modernos.

Esses novos questionamentos propostos pelo autor opõem-se à teoria e prática consolidadas promulgadas por Jenkinson, ou seja, é impossível deixar a seleção dos documentos sob total responsabilidade da administração.

Esse avanço nas discussões teóricas abriu caminhos para novos olhares e novas reflexões dentro da área, possibilitando o desenvolvimento de novas correntes de pensamento.

É o caso da escola canadense, considerada por alguns como moderna e identificada como "Arquivologia Pós-Moderna" ou "Arquivística Pós-Custodial". Formada basicamente por três frentes de pesquisa: Diplomática Contemporânea com uma visão mais europeia da disciplina e representada por Luciana Duranti; Arquivística Integrada visando à união entre os archivists e os records managers, liderada pelos pesquisadores Jean-Yves Rousseau e Carol Couture, e por fim, a Arquivística Funcional fundamentada nas práticas analíticas e teóricas das 
Ciências Humanas, centrada principalmente nos conceitos de proveniência, avaliação e macroavaliação ${ }^{1}$ e liderada por Terry Cook.

As discussões apresentadas nesse artigo estão inseridas na concepção da Arquivística Funcional, uma vez que questiona alguns conceitos até então considerados como paradigmas na Arquivística, motivados principalmente pelo aumento do uso de tecnologias no contexto de produção e organização dos documentos. É a partir do conceito de avaliação que se fundamentam as novas soluções encontradas para esta nova realidade documental.

Para Brothman (1991) os arquivistas devem reconhecer que os documentos somente têm o valor que lhes é atribuído, seja pelas pessoas que trabalham com eles, no sentido de produção e uso, seja pelos próprios arquivistas, no processo de avaliação documental. Ressalta também, que os arquivistas devem refletir criticamente sobre os aspectos que introduzem na avaliação, pois não considera que seja possível preservar os documentos dos juízos de valor humanos, ou seja, os arquivistas não são imparciais e apolíticos na execução de seus trabalhos.

Outro autor que segue a mesma concepção é Terry Cook (1997) argumentando que no caso dos documentos, principalmente públicos, a avaliação tem aspectos eminentemente políticos. A avaliação supõe uma grande responsabilidade social para os arquivistas. Quando avaliam os documentos, os arquivistas estão nada menos que dando forma ao futuro do nosso patrimônio documental. Estão determinando aquilo que o futuro conhecerá do seu passado, que é frequentemente o nosso presente (COOK, 2003).

O autor é bastante enfático quando diz que a avaliação é o único objetivo arquivístico, sendo uma atividade polêmica que requer sensibilidade, além de ter um caráter filosófico e político. E completa, afirmando que os arquivistas literalmente criam arquivos, uma vez que estão decidindo o que deve ser lembrado e o que deve ser esquecido, quem é visível na sociedade e quem é invisível, quem tem voz e quem não; ao se eliminar os documentos, estamos de forma taxativa e irrevogável excluindo dos arquivos e apagando-os da memória (COOK, 2003).

Percebe-se uma mudança no paradigma da avaliação, bem como, nas atribuições do arquivista. Inicialmente, a avaliação era função dos administradores, depois passou a ser responsabilidade dos arquivistas. Isto refletiu no entendimento do seu próprio conceito e prática.

Schellenberg considerava que o documento deveria ser entendido pela função pela qual foi gerado, os valores atribuídos deveriam referir-se ao seu potencial de uso, e a avaliação não poderia ser permeada pela subjetividade, e sim, fundamentada em valores consistentes; já

\footnotetext{
${ }^{1} \mathrm{O}$ conceito de macroavaliação será discutido no item 3.1.
} 
para os pesquisadores canadenses, o valor atribuído aos documentos está intimamente ligado aos valores intrínsecos de quem atribui tal valor, ou seja, trata-se de uma atribuição regida pela subjetividade, e muitas vezes por interesses políticos, sendo assim, de acordo com estes pesquisadores, o arquivista não é um profissional neutro, pelo contrário, os seu pressupostos estão presentes em seus fazeres profissionais, mesmo que inconscientemente.

Atualmente há um grande embate em relação a essas questões, a Arquivística tradicional apresenta dificuldades em aceitar esta nova visão dos arquivistas canadenses. Isto reflete inevitavelmente nas discussões nacionais, onde ainda é muito forte a influência da arquivística tradicional, tanto nas práticas profissionais, instituições de arquivo e no ensino superior.

Este modo de compreender o conceito de avaliação será discutido de maneira mais aprofundada a seguir.

\subsection{0 conceito de Macroavaliação de Terry Cook}

O conceito de macroavaliação (macroappraisal) foi proposto por Terry Cook primeiramente no texto Mind over Matter: Towards a new Theory of Archival Appraisal, publicado em $1992^{2}$.

Segundo Tognoli (2010, p.78) Cook foi influenciado diretamente pelas ideias de David Bearman (1986) e suas concepções acerca do poder do princípio da proveniência e a importância do estudo do contexto muito mais do que o conteúdo; por Tom Nesmith (1982) e seus estudos acerca da história do documento e pela historiografia social de Hugh Taylor (1988). Ainda de acordo com a autora, Cook ignorava as concepções e o paradigma Schellenberguiano de avaliação, indo de encontro ao estabelecimento do valor histórico do documento baseado no conteúdo do assunto.

Sendo assim, o conceito foi desenvolvido buscando um enfoque planejado, estratégico, holístico, sistemático e comparativo para a investigação e identificação das necessidades da sociedade a respeito dos documentos. Com o objetivo de localizar os documentos de valor arquivístico e não apenas como uma reação passiva a solicitações dos gestores para obter autorização para eliminação de documentos.

O objetivo é modificar os vários enfoques da avaliação segundo o conteúdo dos documentos, por um plano mais amplo ou macro, que mostra as funções dos produtores, seus

\footnotetext{
${ }^{2}$ A macroavaliação foi desenvolvida por Terry Cook entre 1989-1990, e o termo macroappraisal foi primeiramente proposto pelo autor no texto Mind over Matter: Towards a new Theory of Archival Appraisal,publicado em 1992, em uma coleção de ensaios (TOGNOLI, 2010, p.77).
} 
programas, ações e negociações, isto é, acentuar a conexão entre os documentos e o motivo de sua criação. Nesse sentido, há uma mudança de foco, da informação e o conteúdo informacional documental para o do conhecimento e seu contexto de criação.

Na macroavaliação o foco inicial muda: o mais importante no momento da avaliação não é o documento (ou qualquer característica ou valores que possa ter), mas sim o contexto funcional no qual se cria o documento (sua origem contextual). Esse contexto baseado na procedência não é a tradicional 'unidade administrativa de origem' e sim a complexa organização administrativa-cultural na qual se insere a produção e conservação de documentos nas instituições modernas.

Sendo assim, o arquivista deve avaliar o universo funcional e estrutural em que o produtor do documento o cria e o utiliza. Trata-se de um processo inevitavelmente subjetivo, onde os valores institucionais e sociais que a expressam mudam com o tempo, o lugar e a cultura. Diante de tal complexidade, os arquivistas e as instituições devem ser considerados responsáveis por suas decisões mediante um relato completo e claro do processo de avaliação seguido e das conclusões obtidas.

Em Macroappraisal in Theory and Practice: origins, characteritiscs, and Implementation in Canada, 1950-2000, Cook (2005 apud TOGNOLI, 2010, p.79) propõe cinco passos principais que devem pressupor a implantação da macroavaliação:

(1) Uma pesquisa sobre a complexidade e a importância relativa das várias subfunções, programas, e atividades dentro do alvo funcional compreendido, objeto da macroavaliação;

(2) Uma pesquisa que localize com precisão o local estrutural onde a maioria dessas funções ou sub-funções acontece;

(3) Uma pesquisa para entender a natureza e as expressões mais utilizadas pelos cidadãos que interagem com essas funções ou programa;

(4) Formação de uma hipótese de macroavaliação sobre o local onde estão os melhores documentos, o que eles globalmente e conceitualmente deveriam ser; e quais funcionalidades significantes da governança eles deveriam documentar; e

(5) Teste e confirmação dessa hipótese avaliando funcionalmente tipos selecionados de documentos dentro do programa funcional que está sendo avaliado, e avaliando o valor dos documentos que estão fora do programa de macroavaliação.

A macroavaliação permite que mais de uma história seja contada, uma vez que os pósmodernistas acreditam que não exista apenas uma única narrativa na série documental, mas sim, muitas histórias, que servirão para públicos diferentes, em momentos e lugares diferentes (TOGNOLI, 2010). 
Nesta nova proposta para o processo avaliativo, o arquivista exerce papel fundamental, uma vez que deve ter consciência ao instituir as políticas de avaliação, que ao selecionar os documentos que serão preservados ou não está elegendo e consequentemente, construindo do passado que o futuro reconhecerá, ou seja, está construindo a memória de uma instituição ou sociedade. Para Cook (2006, p. 103, tradução nossa) "nós, arquivistas, estamos literalmente coproduzindo os arquivos. Nós estamos fazendo história. Estamos exercendo o poder sobre a memória".

\title{
4. O PROCESSO DE AVALIAÇÃO DOCUMENTAL
}

A avaliação consiste fundamentalmente em identificar valores e definir prazos de retenção dos documentos de arquivo - independentemente do suporte - na fase corrente e intermediária, definindo assim as possibilidades de eliminação, microfilmagem e recolhimento aos arquivos permanentes. É recomendado que seja realizada no momento da produção, juntamente ao trabalho de classificação ${ }^{3}$, para evitar a acumulação desordenada.

É na avaliação que os documentos deixam a sua função primária (administrativa, legal e/ou fiscal) para adquirir valor secundário (informativo e probatório), ou seja, momento que o documento cumpriu sua função primária e passa a ser de interesse de pesquisadores e historiadores como fonte de pesquisa para a reconstrução da memória.

\begin{abstract}
A avaliação deve ser realizada dentro de parâmetros técnicos e jurídicos, a fim de se assegurar ao processo de análise a objetividade possível. Por isso, observa-se, de um lado, a legalidade (a conformidade dos prazos de guarda com a legislação vigente) e, por outro, a legitimidade (a elaboração multidisciplinar e coletiva de critérios). Além disso, o trabalho almeja um estatuto científico, pois deve ser conduzido por técnicas, princípios e conceitos consagrados pela Arquivística. Importante registrar que se a objetividade total não é alcançável, não apenas na Arquivística, mas em qualquer área do conhecimento humano, ao menos, se observados esses parâmetros, a subjetividade será reduzida a níveis toleráveis (BERNARDES; DELATORRE, 2008, p.35).
\end{abstract}

O importante é reconhecer que a guarda do documento decorre do valor que ele possui ou que lhe é atribuído, seja por atos legais ou institucionais e a execução de tal avaliação é realizada por meio da Tabela de Temporalidade.

$\mathrm{Na}$ Tabela de Temporalidade se especifica o destino concedido a cada série documental, quais serão conservadas integralmente, quais serão eliminadas, os prazos de

\footnotetext{
${ }^{3}$ Classificação: recupera o contexto de produção dos documentos, isto é, a função e a atividade que determinou a sua produção e identifica os tipos/séries documentais (BERNARDES; DELATORRE, 2008, p.9).
} 
guarda, qual será o tipo de seleção aplicado e a dimensão ou porcentagem retida (CRUZ MUNDET, 2001, p. 223, tradução nossa). Ou seja, determina o ciclo de vida do documento buscando diminuir a influência, relativismo e a subjetividade profissional e pessoal no processo avaliativo.

É por meio de sua aplicação que a informação será sistematicamente selecionada em função do ciclo de vida que Ihe foi atribuído, e os sistemas utilizados serão periodicamente avaliados, acelerando a comunicação da informação pertinente (ROUSSEAU; COUTURE, 1998, p.68-69). Estes critérios garantem que os documentos sejam analisados a partir dos fundamentos estabelecidos pela disciplina arquivística, mantendo seus parâmetros de eliminação e de recolhimento dos documentos que sejam evidências da administração e que tenham importância para a pesquisa no futuro.

A avaliação consiste em um processo, por considerarmos que se trata de uma fase específica que os documentos passam, também considerado como um momento de transição do valor primário para o valor secundário e também, por se tratar da última fase de transferência. Considerando ainda que ela é pautada na tabela de temporalidade que foi elaborada especificamente para essa atividade com base em diversos elementos que servirão de suporte e justificativa para a decisão tomada. Essa transferência do documento baseado na avaliação é um momento importante da vida do documento, pré-definido pelo fluxo documental.

Portanto, os critérios estabelecidos pela avaliação documental e pela aplicação da tabela de temporalidade garantem teoricamente a preservação dos documentos de caráter permanente, mas até que ponto esses critérios contemplam a preservação do patrimônio documental e consequentemente, refletem e a memória institucional e/ou social?

Para Jardim (1995) as técnicas de seleção e avaliação de documentos não atendem aos pressupostos do conceito/noção de memória, ou seja, não asseguram a guarda dos documentos que refletem a memória social e que poderiam compor o patrimônio documental arquivístico. Sendo assim, questiona-se de que forma o processo avaliativo poderia garantir que essa memória não seja perdida?

Questões como esta envolvem um grau elevado de complexidade. O importante no momento da avaliação é, sem dúvida, ter muito bem esclarecido que tipo de documento deve ser preservado a partir dos interesses tanto da instituição como da comunidade a que se integra. A partir disto, pode-se compreender quais documentos apresentam potencial valor de memória institucional e social.

Defende-se que a memória é um fenômeno construído socialmente conforme afirma Pollak (1992), o mesmo se dá nos arquivos, pois visam atender objetivos sociais, institucionais, 
coletivos ou individuais. $\mathrm{O}$ autor utiliza o termo construção, para se referir a atos conscientes ou inconscientes. Ou seja, no momento que os arquivistas realizam a avaliação ou elaboram a tabela de temporalidade estão exercendo o poder de construir a memória, a partir do momento que o documento é um agente ativo na formação da memória humana e organizacional.

De acordo com Terry Eastwood (2003) o documento possui valor social em uma sociedade democrática, de modo que a avaliação deve satisfazer a necessidade que os cidadãos têm de saber como se tem governado e deve permitir compreender o lugar que ocupam dentro da comunidade que se consideram membros, incluída, também, a comunidade nacional.

Os arquivistas devem aceitar seu papel dentro do processo social e contextual de criação dos documentos. Eles devem entender que o documento é a memória da sociedade, que deve ser amplamente compartilhada. "Os arquivistas servem à sociedade, não ao Estado" (COOK, 2001, p. 19).

\section{A NEUTRALIDADE DO ARQUIVISTA NO PROCESSO DE AVALIAÇÃO}

Ao trabalharmos a questão da avaliação documental fica evidente a importância do papel do arquivista neste processo. Atualmente, é bastante questionável e discutida sua neutralidade e imparcialidade no momento da seleção e da avaliação e a possível interferência de interesses sociais, intelectuais, culturais, institucionais e políticos (durante a execução do trabalho).

Jenkinson (1922) e Schellenberg (2002) consideram o arquivista como profissional totalmente imparcial e neutro de qualquer tendência política ou ideológica, muitas vezes é referenciado como o "guardião da verdade".

Schellenberg também argumenta: o trabalho do arquivista, em qualquer época, é preservar imparcialmente o testemunho, sem contaminação de tendências políticas e ideológicas, de forma que, tomando-se por base esse testemunho, os julgamentos sobre homens e fatos que os historiadores, por deficiências humanas, estejam momentaneamente incapacitados de proferir, possam ser proferidos pela posteridade. E ainda, conscientes de seu papel na preservação das informações no documento autêntico e crível.

A antiga visão dos autores não condiz mais com a realidade atual, o arquivista não pode mais ser visto como um simples guardião dos documentos, imparcial e neutro. Para Cook $(1998$, p. 140) nem o arquivista, nem o documento podem ser considerados de tal forma, uma vez que: 
Nada é neutro. Nada é imparcial. Tudo é moldado, apresentado, representado, simbolizado, significado, assinado, por aquele que fala, fotografa, escreve, ou pelo burocrata governamental, com um propósito definido, dirigido a uma determinada audiência.

O autor faz esta afirmação baseado nas mudanças ocorridas nas diversas organizações, públicas e privadas, e nas formas de registro e processamento dos arquivos, e considerando, também, o contexto em que vivemos e as novas formas de gerar conhecimento sobre a história e o novo caráter adquirido pela memória. Segundo ele, a própria natureza dessas mudanças conceituais transforma a tarefa dos arquivistas, tanto dos arquivos institucionais quanto dos pessoais, e oferece uma perspectiva compartilhada sobre arquivos que, por sua vez, pode levar a uma nova unidade nos esforços da arquivística, centrada na formação da memória da sociedade (COOK, 1998).

Le Goff $(1986$, p.86) já defendia essa ideia quando reflete sobre a questão do documento e da memória: “[...] temos claro que não conferimos qualquer grau de 'neutralidade' aos documentos, anotando-se que estes devem ser objeto de crítica, e sua recordação e leitura evocam memórias igualmente construídas". Divergindo da historiografia tradicional, o autor aponta que "o documento nunca é o simples resultado de uma situação histórica dada". É preciso analisar, então, as condições de produção do documento: "em que é que está ligado a um caráter fundamental de toda a sociedade, quer dizer, a tentativa consciente ou inconsciente de hipotecar o futuro".

Cook (1998) reafirma dizendo que nenhum texto é um mero subproduto, e sim um produto consciente para criar uma persona ou servir a um propósito, embora essa consciência, ou persona, ou propósito - esse contexto por trás do texto - possa ser transformado, ou perdido, em padrões inconscientes de comportamento social, em discurso institucional e em fórmulas padronizadas de apresentação de informações.

Seja no âmbito da avaliação, ou em qualquer outro fazer profissional, o arquivista carrega, consciente ou inconscientemente, seus atributos pessoais e profissionais, ou seja, a prática profissional está fundamentada nesses aspectos que interferem diretamente na execução de seu trabalho.

Em relação, a competência de construtor da memória, é sim de sua responsabilidade eleger o que será esquecido e o que será lembrado. Logo, devem-se aprofundar as discussões acerca da atribuição dos valores aos documentos e verificar se há realmente interferência de aspectos subjetivos na construção da memória. 


\section{CONSIDERAÇOES FINAIS}

A avaliação documental é considerada como aporte para a construção da memória. Dentro das instituições públicas ou privadas ela garante o encaminhamento dos documentos de valor secundário ao arquivo permanente.

Diante das diferentes colocações dos autores podemos compreender que o processo avaliatório dos documentos de arquivo pode se tornar responsável pela formação do patrimônio arquivístico. Mas para apreender de que forma este patrimônio expressa e narra a memória social é necessário uma análise mais profunda de diversos aspectos que não foram objeto de análise deste trabalho.

Para Jardim (1995) faz-se necessário que a arquivologia debruce-se sobre o tema da memória de modo a favorecer uma revisão dos aspectos teóricos e metodológicos da avaliação e seleção de documentos. Parece urgente, no mínimo, operar com uma noção/conceito de memória que privilegie os seus aspectos como construção social, e não como dado arqueologizável.

Nesse sentido, a multiplicidade de abordagens teóricas desses conceitos e noções e a sua relação com os arquivos fazem com os profissionais da informação, de uma maneira geral e não só os arquivistas, reflitam, reconsiderem e revisem o papel, a missão e a relevância dos estudos de avaliação no âmbito da gestão e preservação dos documentos de arquivo.

\section{Referências}

ARQUIVO NACIONAL (Brasil). Conselho Nacional de Arquivos Classificação, temporalidade e destinação de documentos de arquivo; relativos às atividades-meio da administração pública. Rio de Janeiro: Arquivo Nacional, 2001. p. 156. Disponível em:

<http://www.conarq.arquivonacional.gov.br/media/publicacoes/cdigo de classificacao.pdf > Acesso em: 10 de nov. 2012.

BERNARDES, I. P.; DELATORRE, H. Gestão Documental Aplicada. São Paulo: Arquivo Público do Estado de São Paulo, 2008. 54 p. Disponível em:

$<$ http://www.arquivoestado.sp.gov.br/saesp/GESTAO DOCUMENTAL APLICADA leda.pdf>. Acesso em: 05 jan. 2011.

BROTHMAN, B. Orders of value: Probing the theoretical terms of archival practice. Archivaria, v.32, 1991, p.78-100. Disponível em:

< http://journals.sfu.ca/archivar/index.php/archivaria/article/viewArticle/11761>. Acesso em: 10 de nov. 2012. 
COLOMBO, F. Os arquivos imperfeitos: memória social e cultura eletrônica. São Paulo: Perspectiva, 1986.

COOK, T. What is past is prologue: a history of archival ideas since 1898, and the future paradigm shift. Archivaria, v. 43, 1997(Spring), p. 18-63. Disponível em:

< http://www.mybestdocs.com/cook-t-pastprologue-ar43fnl.htm>. Acesso em: Acesso em: 10 nov. 2012.

- Arquivos pessoais e arquivos institucionais: para um entendimento comum da formação da memória em um mundo pós-moderno. Estudos históricos, Rio de Janeiro, v. 11, n. 21, p. 129-150, 1998. Disponível em: <http://www.cpdoc.fgv.br/comum/htm/ >. Acesso em: 10 nov. 2012.

. Archival science and postmodernism: new formulations for old concepts. Archival Science: International Journal on Recorded Information, v.1, n. 1, 2001, p. 3-24. Disponível em: $<$ http://www.polonistyka.uj.edu.pl/documents/41623/111f093d-a2af-4fc6-8f9ae193d85712a5>. Acesso em: 15 jun. 2012.

Macrovaloración y análisis funcional: la preeminencia de la interacción políticosocial sobre el gobierno. Tabula: Revista de Archivos de Castilla y León / Asociación de Archiveros de Castilla y León. Salamanca, n. 6, p.87-103, 2003.

Macroappraisal in Theory and Practice: origins, characteristics, and implementation in Canada, 1950-2000. Archival Science: International Journal on Recorded Information, v. 5, 2005, p. 101-161.

CRUZ MUNDET, J. R. Manual de archivística. 4. ed. Madrid: Fundación Germán Sánchez Ruipérez, 2001.

EASTWOOD, T. La valoración archivística en las sociedades democráticas. Tabula: Revista de Archivos de Castilla y León / Asociación de Archiveros de Castilla y León. Salamanca, n. 6, 2003.

JARDIM, J. M. A invenção da memória nos arquivos públicos. Ciência da Informação, Brasília, v.25, n.12, p.1-13, 1995. Disponível em:

$<$ http://revista.ibict.br/ciinf/index.php/ciinf/article/viewFile/439/397>. Acesso em: 05 jan. 2011.

JENKINSON, H. A manual of archive administration: including the problems of war archives and archive making. Oxford: The Clarendon Press, 1922.

LE GOFF, J. Reflexões sobre a história. Lisboa: Edições 70, 1986.

LOPES, L. C. A nova arquivística na modernização administrativa. 2.ed. Brasília: Projecto Editorial, 2009.

MARTINS, M. do C. Os desafios para a organização do Centro de Memória da Educação da UNICAMP, ou de como constituir coletivamente um "lugar de memória". In: CONGRESSO LUSO-BRASILEIRO DE HISTÓRIA DA EDUCAÇÃO: IGREJA, ESTADO, SOCIEDADE CIVIL, INSTÂNCIAS PROMOTORAS DE ENSINO, 5., 2004, Évora. Anais... Évora: Universidade de Évora/Artipol, 2004.

MENESES, U. B. de. O patrimônio cultural entre o público e o privado. In: 0 direito à memória: patrimônio histórico e cidadania. São Paulo: Departamento do Patrimônio Histórico/Secretaria Municipal da Cultura/Prefeitura do Município de São Paulo, 1992. 
POLLAK, M. Memória e identidade social. Estudos Históricos, Rio de Janeiro, v.5, n.10, p. 200212, 1992. Disponível em:

http://reviravoltadesign.com/080929 raiaviva/info/wp-gz/wpcontent/uploads/2006/12/memoria e identidade social.pdf>. Acesso em: 05 jan. 2012.

ROUSSEAU, J. I.; COUTURE, C. Os fundamentos da disciplina arquivística. Lisboa: Dom Quixote, 1998.

SCHELLENBERG, T. R. Documentos públicos e privados: arranjo e descrição. 2 ed. Rio de Janeiro: FGV, 2002.

Modern Archives: Principles and Techniques, 1956.

TOGNOLI, N. B. A contribuição epistemológica canadense para a construção da Arquivística contemporânea. Dissertação (Mestrado em Ciência de Informação) - Universidade Estadual Paulista, Marília, 2010. Disponível em: < http://www.athena.biblioteca.unesp.br/exlibris/bd/bma/33004110043P4/2010/tognoli nb m e mar.pdf $>$. Acesso em 10 jan. 2011.

Submetido em: 12/2012 